\title{
Synthesis and Characterisation of Metallosurfactants as Carbon Dioxide Viscosity Modifier
}

\author{
Khadega R Abdosalam \& Azmi Mohamed* \\ Department of Chemistry, Faculty of Science and Mathematics, University Pendidikan Sultan Idris, \\ 35900 Tanjong Malim, Perak, Malaysia
}

*Corresponding Author: azmi.mohamed@fsmt.upsi.edu.my

\begin{abstract}
This paper focuses on a systematic approach to enhance the viscosity of supercritical $\mathrm{CO}_{2}\left(\mathrm{scCO}_{2}\right)$ for enhanced recovery applications. Recent successful results have shown for the first time that fluorinated surfactants can be used as viscosity modifiers for $\mathrm{CO}_{2}$. Although some fluorinated surfactants have been synthesised, up to now no systematic studies have been carried out toward $\mathrm{scCO}_{2}$ viscosity enhancement and impeded commercial developments of viscosity modifier. Here, metallosurfactant structure design was focused on anionic surfactant analogues of Aerosol -OT (sodium bis (2-ethyexyl) sulfosuccinate). The metallosurfactant were systematically synthesised with modification centred on fluorinated content in surfactant chain with introduction of nickel $\left(\mathrm{Ni}^{2+}\right)$ and manganese $\left(\mathrm{Co}^{2+}\right)$ counter ions. The metallosurfactant have been investigated by a range of techniques including Nuclear Magnetic Resonance (NMR) Spectroscopy, UV-Visible Spectroscopy and High-Pressure Viscometer. The result shows that fluorination is a crucial factor influencing Aerosol-OT surfactant analogue compatibility with $\mathrm{scCO}_{2}$. The presence of fluorine in the metallosurfactant chemical structure gives rise to relative $\mathrm{scCO}_{2}$ viscosity. The results obtained are beneficial for expanding $\mathrm{CO}_{2}$ in enhanced oil recovery applications and realising its potential using the most efficient metallosurfactant as $\mathrm{CO}_{2}$ viscosity modifier.
\end{abstract}

Keywords: carbon dioxide, viscosity modifier, surfactant.

\section{INTRODUCTION}

Supercritical carbon dioxide $\left(\mathrm{scCO}_{2}\right)$ has received considerable attention as a novel solvent medium due to an easily accessible critical point, at $\mathrm{T}_{\mathrm{c}}=31^{\circ} \mathrm{C}$ and $\mathrm{P}_{\mathrm{c}}=73 \mathrm{bar}$, above which its compressibility leads to solvent qualities (e.g. dielectric constant, density) that are tuneable by $\mathrm{T}$ and $\mathrm{P}-$ a clear advantage over conventional liquid solvents $[1,2]$. In contrast, many other common solvents either have much higher critical temperatures / pressures e.g. water $\left(T_{c}=374{ }^{\circ} \mathrm{C}\right.$ and $\left.P_{c}=221 \mathrm{bar}\right)$, toluene $\left(T_{c}=319{ }^{\circ} \mathrm{C}\right.$ and $P_{c}=41 \mathrm{bar}$ ); or are flammable (and therefore regulated) e.g. ethane with $T_{c}=32{ }^{\circ} \mathrm{C}$ and $P_{c}=49$ bar [3]. Due to the low or zero heat of vaporisation of its liquid or supercritical states, $\mathrm{scCO}_{2}$ is also easily recovered (and therefore recycled) after use by depressurisation, removing the requirement for solvent removal / drying steps [1]. Commercial applications of $\mathrm{scCO}_{2}$ as a solvent have already been demonstrated in several industries [4], including speciality cleaning (dry-cleaning, de-greasing of high value items), extraction (decaffeination, extraction of volatile fragrance compounds), and even refrigeration for home air conditioning systems. However, these applications have so far been restricted to highly specialised, niche markets, mainly due to the poor solvent quality of this weak, non-polar solvent $[5,3]$. To realise the full economic and environmental potential of $\mathrm{scCO}_{2}$, creative new approaches to modify its physico-chemical properties are required, including improvement of the solvent quality by the incorporation of polar domains using surfactants or polymers $[4,3]$; by influencing other solvent properties e.g. viscosity, for applications such as oil recovery [6]; or by the dispersion of e.g. catalytically active inorganic materials to form a catalytic system with facile product recovery $[7,8]$. 
In oil and gas industry, $\mathrm{scCO}_{2}$ is commonly used for fracture simulation and enhanced oil recovery (EOR). Despite the promising utilisation of $\mathrm{sc}-\mathrm{CO}_{2}$ in EOR, it is not without its own problem. The low viscosity of $\mathrm{scCO}_{2}$ poses as a hindrance in terms of EOR efficiency that will affect the optimum oil production [9]. Even as fracturing fluid, this poor viscosity may become the factor of proppant settling and fluid leak-off that might give disadvantages for the process efficiency. These manifold drawbacks in applying scCO2 therefore must be addressed to facilitate the $\mathrm{CO}_{2}$-based industry. All this may be overcome by thickening the viscosity of $\mathrm{scCO}_{2}[9]$.

During many years, studies on $\mathrm{CO}_{2}$-compatible compounds hinted the promising result when fluorine is present on the compounds molecular structure. Huang and co-workers used copolymers of fluoroacrylate and styrene as modifier and they predicted up to 20 -fold thickening of $\mathrm{scCO}_{2}$ viscosity at copolymer concentrations around $1.0 \mathrm{wt} \%$. [10]. Along similar lines, Shi and co-workers (2001) used another fluorinated compounds; fluorinated telechelic ionomer to increase the viscosity of dense $\mathrm{CO}_{2}$ by 2 to 3 fold without the need of co-solvent at ionomer concentration of $2-4 \mathrm{wt} \%$ (Shi et al., 2001). Other $\mathrm{CO}_{2}$ thickener based on polyfluoroacrylate polymer, was also reported to provide significant enhancement without the help of co-solvent $[10,11]$. All these materials reported above, however, contained highly fluorinated compounds that are both expensive and environmentally harmful.

This paper focuses on a systematic approach to understand what molecular criteria may be used to increase the viscosity of supercritical $\mathrm{CO}_{2}\left(\mathrm{scCO}_{2}\right)$ for enhanced recovery applications. Recent successful results have shown for the first time that fluorinated surfactants can be used as viscosity modifiers for $\mathrm{CO}_{2}$ [12]. Although some surfactants have been synthesised and used successfully with $\mathrm{CO}_{2}$, lack of carbon dioxide viscosity enhancement properties have impeded their commercial developments. Thus, the challenge of developing fluorinated surfactants as viscosity modifiers remains a challenge. Recently, very promising low fluorine content surfactants have been identified that can stabilise water-in- $\mathrm{CO}_{2}(\mathrm{w} / \mathrm{c})$ microemulsions $[13,14,15]$. Interestingly, this is the first time that these transition metal counterions have been incorporated into low fluorine $\mathrm{CO}_{2}$-philic surfactants or recognised as metallosurfactants and systematically studied in $\mathrm{scCO}_{2}$. Thus, the introduction of transition metal counterions to low fluorine content surfactants or metallosurfactants represents an exciting new approach and experimental data are essential in order to investigate whether these compounds represent new economical and effective surfactants for $\mathrm{scCO}_{2}$ viscosity enhancement in enhanced oil recovery applications.

Table 1 Double-chain fluorinated sulfosuccinate surfactants used in this study

Surfactant




\section{MATERIALS AND METHODS}

\section{Materials}

All chemicals were of analytical reagent grade and used as received. Chemicals and reagents that were used as follows: Alcohol precursor: $1 \mathrm{H}, 1 \mathrm{H}, 5 \mathrm{H}$-perfluoropentanol (Apollo Scientific), $1 \mathrm{H}, 1 \mathrm{H}, 7 \mathrm{H}$ perfluoroheptanol (Apollo Scientific), 4H, 4H, 5H, 5H ,5H- pentafluoropentanol (Apollo Scientific); Chemical precursor: Maleic anhydride (Friendemann Schmidt), p-toluene-4-sulfonic acid monohydrate 98\% (Merck), sodium hydrogen sulfite (Friendemann Schmidt), nickel (II) nitrate 98\% (Sigma Aldrich), Cobalt (II) Nitrate 98\% (Sigma Aldrich); Solvent: toluene 99.5\% (Systerm), n-hexane 99\% (Systerm), ethyl acetate 99.5\% (Systerm), 1,4-dioxane 99\% (Systerm), acetone 99.5\% (Systerm), ethanol 99\% (Systerm), diethyl ether 99\% (Systerm). $\mathrm{CO}_{2}$ 99.99\% purity (Nippon Ekitan Co., Ltd.) was used without further treatment.

\section{Surfactant Synthesis}

\section{Synthesis of Double-chain Fluorinated Sulfosuccinate Surfactants}

The experiment involved four main steps: esterification, purification of diester, sulfonation, and purification of surfactant.

\section{Esterification}

A mixture of alcohol (2.2 eq), maleic anhydride (1.0 eq), p-toluene-4-sulfonic acid monohydrate (0.2 eq), and toluene $(100 \mathrm{~mL}$ per maleic anhydride), were heated overnight under reflux conditions using a Dean and Stark apparatus. Water was removed azeotropically during the reaction to induce a chemical equilibrium shift. The reaction was considered complete when the amount of water collected in the trap was comparable to the theoretical amount, then washed using warm water $\left(70^{\circ} \mathrm{C}\right)$ to remove excess maleic anhydride and p-toluene-4-sulfonic acid monohydrate $(0.2 \mathrm{eq})$. Solvent was removed using a rotary evaporator and the diester was obtained as a yellow liquid.

\section{Purification of Diester (Column Chromatography)}

Column chromatography was prepared by using silica powder $\left(\mathrm{SiO}_{2}\right)$ with solvent $(33 \%$ ethyl acetate in n-hexane). Diester was loaded into the column and flushed using the above solvent composition. Thin layer chromatography (TLC), was used to assess the composition, showed a characteristic spot about two thirds of the way along the plate. Removal of solvents was performed using a rotary evaporator. A lightyellow liquid was obtained as the pure diester.

\section{Sulfonation}

The diester was first dissolved using 1,4 dioxane for the fluorinated diesters, and water was added to the mixture until saturation. Sodium hydrogen sulfite $(2.0 \mathrm{eq})$, was added to the mixture and the reaction was allowed to continue for about 7-9 hours. Surfactant formation was monitored using TLC. The reaction was considered complete with the disappearance of the diester spot and the appearance of a crude surfactant spot in the baseline. Crude surfactant was obtained after solvent removal using rotary evaporation and dried overnight in an oven at $80{ }^{\circ} \mathrm{C}$.

\section{Purification of Surfactants}

The first step of the purification was to dissolve the crude surfactant in dried acetone. The crude surfactant was dissolved whilst stirring for two hours to obtain the maximum yield. Solvent was removed using a rotary evaporator and a white solid product was obtained. Inorganic impurities were removed by centrifugation at $5200 \mathrm{rpm}$ for 20 minutes. Solvent was removed from the remaining solid using a rotary evaporator. All purified surfactants were characterized using ${ }^{1} \mathrm{H}$ Nuclear Magnetic Resonance (NMR) Spectroscopy (JEOL $550 \mathrm{MHz}$ ) and Elemental Analysis (Thermofinnigan). 


\section{Preparation of $\left(\mathrm{Ni}^{2+}\right.$ or $\left.\mathrm{Co}^{2+}\right)$ Metallosurfactants $\left(\mathrm{M}^{2+}\right.$ - surfactant $)$}

Saturated solutions of metal $\left(\mathrm{Ni}^{2+}\right.$ or $\left.\mathrm{Co}^{2+}\right)$ nitrates were prepared by dissolving $(50 \mathrm{~g})$ of salt in $(20 \mathrm{~mL})$ water. Metal ion $\left(\mathrm{Ni}^{2+}\right.$ or $\left.\mathrm{Co}^{2+}\right)$ exchanged surfactants were prepared according to previously published methods $[16,17,18] . \mathrm{Na}^{+}$-surfactant was dissolved in $20 \mathrm{~mL}$ of absolute ethanol at $1 \mathrm{~mol} \mathrm{dm}^{-3}$. Saturated solution was added into $\left(\mathrm{Na}^{+}\right.$-surfactant) and stirred for one hour. Then, $20 \mathrm{~mL}$ of diethyl ether was added and shaken in a separating funnel to produce two phases. The upper diethyl ether phase contained $\mathrm{M}^{2+}$-surfactant and the lower phases were removed. The upper phase was washed repeatedly with water until a colourless solution was obtained. The above process was monitored by UV-Visible Spectroscopy (Agilent).

\section{High-Pressure Phase Behaviour of Metallosurfactants and Supercritical $\mathrm{CO}_{2}$ Viscosity Measurements}

The phase behaviour of the synthesised surfactants and supercritical $\mathrm{CO}_{2}$ viscosity enhancement were examined through high-pressure cell measurement at temperatures ranging from 35 to $75^{\circ} \mathrm{C}$. A known amount of surfactants in $\mathrm{w} / \mathrm{scCO}_{2}$ mixtures was visually observed to record the phase behaviour of the system. Observations of phase changes were examined in a high-pressure vessel with an optical window and a moving piston inside. Measurements were conducted with an invariable composition, varying the temperature and pressure of the mixture. $0.05 \mathrm{~mol} \mathrm{dm}^{-3}$ surfactant and defined amount of $\mathrm{CO}_{2}$ were placed in an optical cell and equilibrated overnight with vigorous stirring at $75^{\circ} \mathrm{C}$ and 400 bar to obtain a transparent single phase.

A known amount of water was then introduced into the mixture via the six-port valve. The formation of a clear mixture with a water content greater than its solubility in pure $\mathrm{scCO}_{2}$ is considered to be a microemulsion. Cloud pressures $\left(\mathrm{P}_{\text {trans }}\right)$ were observed when the clear mixture became turbid as the pressure was adjusted and the microemulsions $(1 \Phi)$ transformed into macroemulsions $(2 \Phi)$. The amount of water dispersed in $\mathrm{CO}_{2}$ was expressed as the water-to-surfactant molar ratio $(w) . \mathrm{CO}_{2}$ densities were calculated using the Span-Wagner EOS [19, 20].

\section{RESULTS AND DISCUSSION}

\section{di-HCF4 surfactant}

${ }^{1} \mathrm{HNMR}$ (550 MHZ, $\left.\mathrm{CDCl}_{3}, \mathrm{TMS}\right), \quad\left(\delta_{\mathrm{H}} / \mathrm{ppm}\right): \quad 3.04-3.29(\mathrm{a}, \mathrm{m}, 2 \mathrm{H}), 4.46(\mathrm{~b}, \mathrm{~m}, 1 \mathrm{H}), 4.40-4.66$ (c, $\mathrm{m}, 4 \mathrm{H}), 5.69-5.69(\mathrm{~d}, \mathrm{~m}, 4 \mathrm{H})$. Elemental Analysis: found C, 25.94; H, 1.40; S,4.95. Calcd C, 24.24; H,1.14; $\mathrm{S}, 4.54$.

di-HCF6 surfactant

${ }^{1} \mathrm{HNMR}\left(550 \mathrm{MHz}, \mathrm{CDCl}_{3}, \mathrm{TMS}\right),\left(\delta_{\mathrm{H}} / \mathrm{ppm}\right): 3.29-3.04(\mathrm{a}, \mathrm{m}, 2 \mathrm{H}), 4.46$ (b.m,1H), 4.66-4.40(c, m,4H), 5.69-5.69(d, m,4H). Elemental Analysis: found C,25.49; H,1.07; S,3.78. Calcd C, 23.28; H,0.76; S,3.15.

\section{di-CF2 surfactant}

${ }^{1} \mathrm{HNMR}\left(550 \mathrm{MHZ}, \mathrm{CDCl}_{3}, \mathrm{TMS}\right),\left(\delta_{\mathrm{H}} / \mathrm{ppm}\right):$ 1.61-1.62(a, m,8H), 3.29-3.04(b, m,2H), 4.08-4.13(c, $\mathrm{m}, 4 \mathrm{H}), 4.46(\mathrm{~d}, \mathrm{~m}, 1 \mathrm{H})$. Elemental Analysis: found C,31.12; H,2.80; S,5.93. Calcd C,30.49; H,2.20; $\mathrm{S}, 3.69$.

\section{UV-Visible Spectroscopy}

The formation of $\mathrm{M}^{2+}$-surfactants was confirmed using UV-Visible spectroscopy. Surfactant formation was confirmed when no further $\mathrm{NaNO}_{3}$ and $\mathrm{M}\left(\mathrm{NO}_{3}\right)_{2}$ were present in the UV-visible absorbance spectra of the washings. Figures $1-2$ show the disappearance with progressive washing (after eight washes) of the two absorbance bands in the UV-visible spectrum, at $305 \mathrm{~nm}$ and $394 \mathrm{~nm}$, which are ascribed to the $\mathrm{n}-\pi^{*}$ transition of the nitrate ion and the d-d transition of $\mathrm{Co}^{2+}$ and $\mathrm{Ni}^{2+}$ (hexa-aqua nickel ion) [21]. 


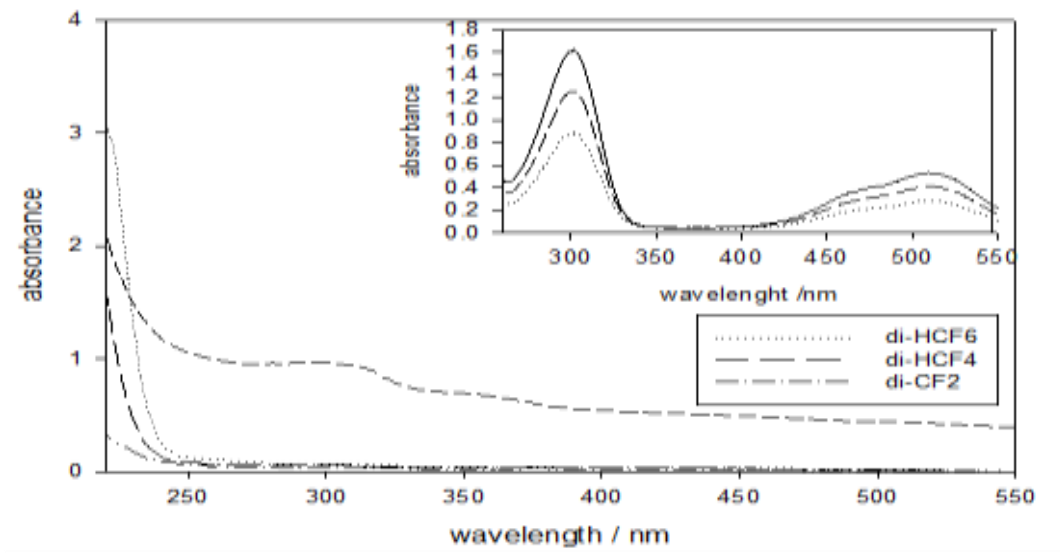

Figure $1 \mathrm{UV}$-visible absorbance spectra of the aqueous washings used to remove $\mathrm{NaNO}_{3}$ and $\mathrm{Co}\left(\mathrm{NO}_{3}\right)_{2}$ impurities from $\mathrm{M}^{2+}$-surfactants. Inset: spectra before the washing process.

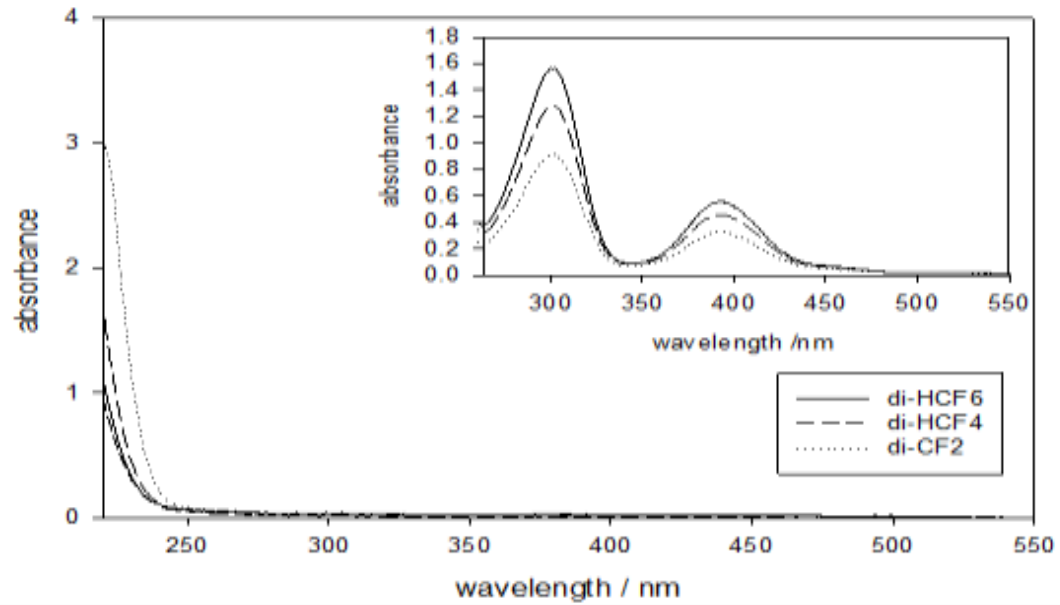

Figure $2 \mathrm{UV}$-visible absorbance spectra of the aqueous washings used to remove $\mathrm{NaNO}_{3}$ and $\mathrm{Ni}\left(\mathrm{NO}_{3}\right)_{2}$ impurities from $\mathrm{M}^{2+}$-surfactants. Inset: spectra before the washing process.

\section{High-Pressure Phase Behaviour of Metallosurfactant- $\mathrm{CO}_{2}$ Systems}

In order to determine the influence of surfactant structure on microemulsion phase stability, the pressure - temperature phase boundaries for the metallosurfactants di-CF2, di-HCF4 and di-HCF6 were determined at a fixed concentration of $0.04 \mathrm{~mol} \mathrm{dm}^{-3}$ and various $w\left(\left[\mathrm{H}_{2} \mathrm{O}\right] /[\right.$ surfactant $\left.]\right)$ mole ratio values. The cloud transition pressure, $\mathrm{P}_{\text {trans }}$ was determined visually as the pressure at which the onset of cloudiness occurred on lowering the pressure at a fixed temperature. Above $\mathrm{P}_{\text {trans }}$, the systems were transparent $(1 \Phi)$ and when the pressure was reduced approaching $\mathrm{P}_{\text {trans }}$, significant cloudiness was observed $(2 \Phi)$. 
Previously, $\mathrm{CO}_{2}$-philicity of surfactants has been achieved by fluorination of surfactant chains. For example, the maximum $w$ loading $\left(w_{\max }\right)$ at accessible temperatures and pressures for di-CF2, di-HF4 and di-HCF6 are summarised in Table 2 . The $w_{\max }$ values indicate that higher fluorine content increases the microemulsifying properties. One approach to enhance the viscosity of the uncooperative solvent $\mathrm{CO}_{2}$ is to introduce metallosurfactant by exchanging $\mathrm{Na}^{+}$cations of a sulfosuccinate surfactant with $\mathrm{Ni}^{2+}$ or $\mathrm{Co}^{2+}$ counter ions [22]. As an initial step, the solubility of $\mathrm{Ni}(\mathrm{diHCF} 4)_{2}$ and $\mathrm{Co}(\mathrm{diHCF} 4)_{2}$ in $\mathrm{CO}_{2}$ was examined at different at $w$ ratios The result was in agreement with earlier work by Trickett et al.[22], with uncertainties in $P_{\text {trans }}$ no greater than 60 bar representing a realistic measure of reproducibility.

Table 2 Phase behaviour measurements of sulfosuccinate surfactants for w/c microemulsions at $35^{\circ} \mathrm{C}, w=10$ and maximum water loading $\left(w_{\max }\right)$. ${ }^{\mathrm{a}}$ Data collected by [13]; ${ }^{\mathrm{b}}$ Data collected by [23].

\begin{tabular}{|c|c|c|}
\hline Surfactants & $\mathbf{P}_{\text {trans }} /$ bar & $w_{\max }$ \\
\hline $\mathrm{Co}(\mathrm{di}-\mathrm{CF} 2)_{2}$ & $>400$ & 5 \\
\hline $\mathrm{Co}(\mathrm{di}-\mathrm{HCF} 4)_{2}$ & 267 & 15 \\
\hline $\mathrm{Co}(\mathrm{di}-\mathrm{HCF} 6)_{2}$ & 165 & 30 \\
\hline $\mathrm{Ni}(\mathrm{di}-\mathrm{CF} 2)_{2}$ & $>400$ & 10 \\
\hline $\mathrm{Ni}(\mathrm{di}-\mathrm{HCF} 4)_{2}$ & 251 & 25 \\
\hline $\mathrm{Ni}(\mathrm{di}-\mathrm{HCF} 6)_{2}$ & 182 & 25 \\
\hline di-CF $2^{\mathrm{a}}$ & 198 & 20 \\
\hline $\mathrm{di}^{-H C F} 4^{\mathrm{a}}$ & 185 & 30 \\
\hline di-HCF4 $4^{b}$ & 239 & 35 \\
\hline di-HCF6 & 149 & 40 \\
\hline di-HCF6 ${ }^{b}$ & 185 & 45 \\
\hline
\end{tabular}

In order to investigate the effect of fluorine content on metallosurfactants, the performance of $\mathrm{Ni}(\mathrm{diHCF} 4)_{2}$ and $\mathrm{Co}(\mathrm{diHCF} 4)$ was compared with the related di-CF2 and di-HCF6 surfactants. As can be seen in Figure $3-8$, decreasing the fluorine content to diCF2 had a significant effect on the w/c phase stability. The $\mathrm{Ni}(\mathrm{diCF} 2)_{2}$ and $\mathrm{Co}(\mathrm{diCF} 2)_{2}$ surfactants apparently result in a much lower $w$ ratio of about $w_{\max }=5$ and $w_{\max }=10$ respectively, compared to the di-HCF4 surfactant. Interestingly, the introduction of $\mathrm{Ni}^{2+}$ or $\mathrm{Co}^{2+}$ counter ions to the higher fluorine content di-HCF6 was shown to have a significant effect on the w/c phase stability. $\mathrm{Co}(\text { diHCF6 })_{2}$ and Ni(diHCF6 $)_{2}$ surfactants were able to stabilise w/c microemulsions with $w_{\max }=30$ and $w_{\max }=25$ respectively. From these results, it was clear that fluorination is indeed necessary to achieve the $\mathrm{CO}_{2}$-philicity.

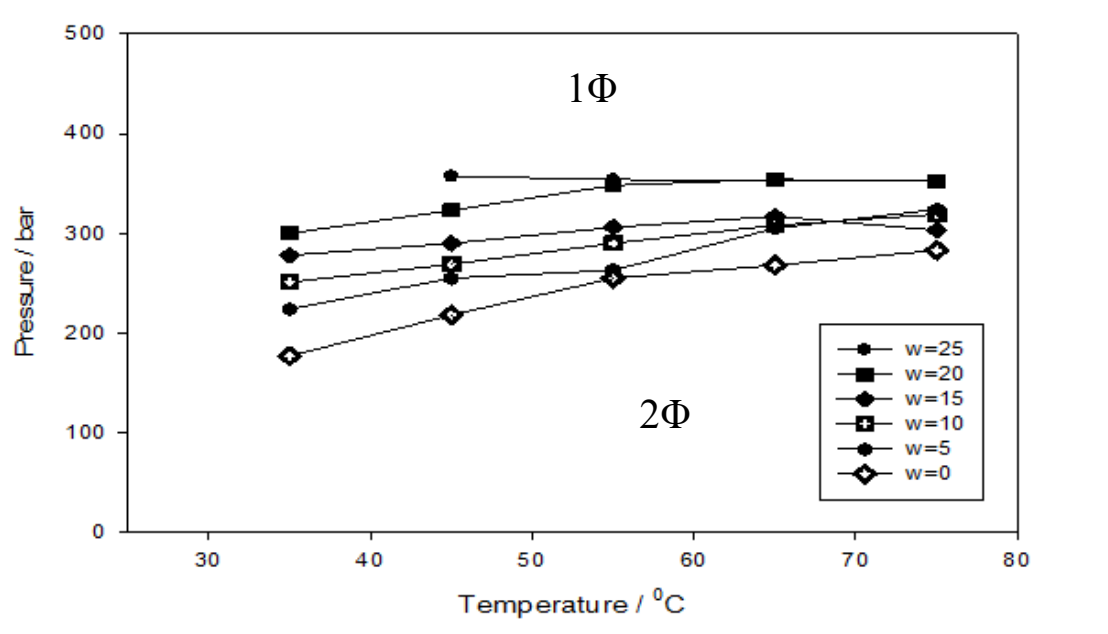

Figure 3 Phase behaviour of $\mathrm{Ni}(\mathrm{di}-\mathrm{HCF} 4)_{2}$ surfactant in $\mathrm{CO}_{2}$ at various $w$ ratios. [surfactant] $=0.04 \mathrm{~mol} \mathrm{dm}^{-3}$ 


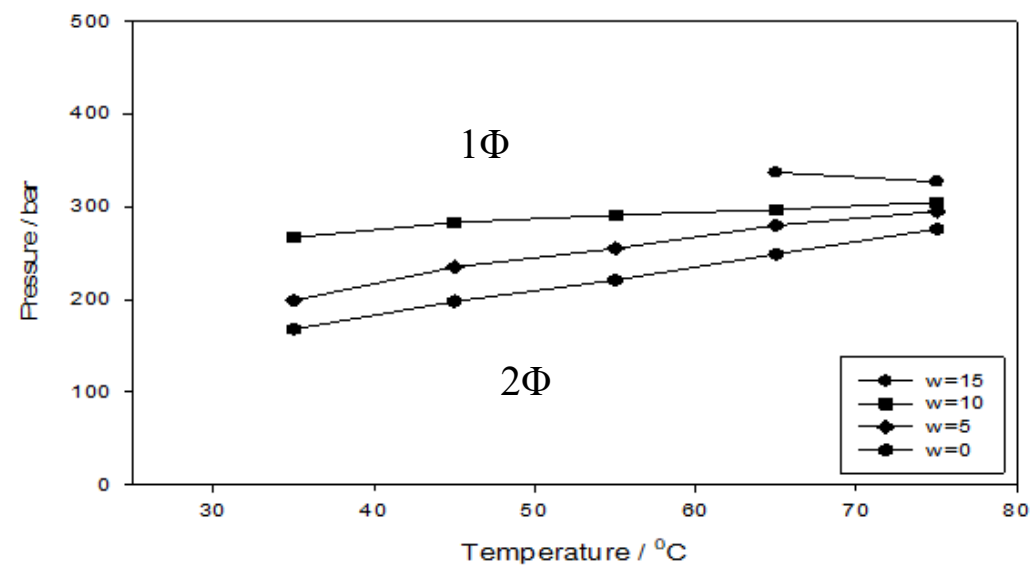

Figure 4 Phase behaviour of $\mathrm{Co}(\mathrm{di}-\mathrm{HCF} 4)_{2}$ surfactant in $\mathrm{CO}_{2}$ at various $w$ ratios. [surfactant] $=0.04 \mathrm{~mol} \mathrm{dm}^{-3}$

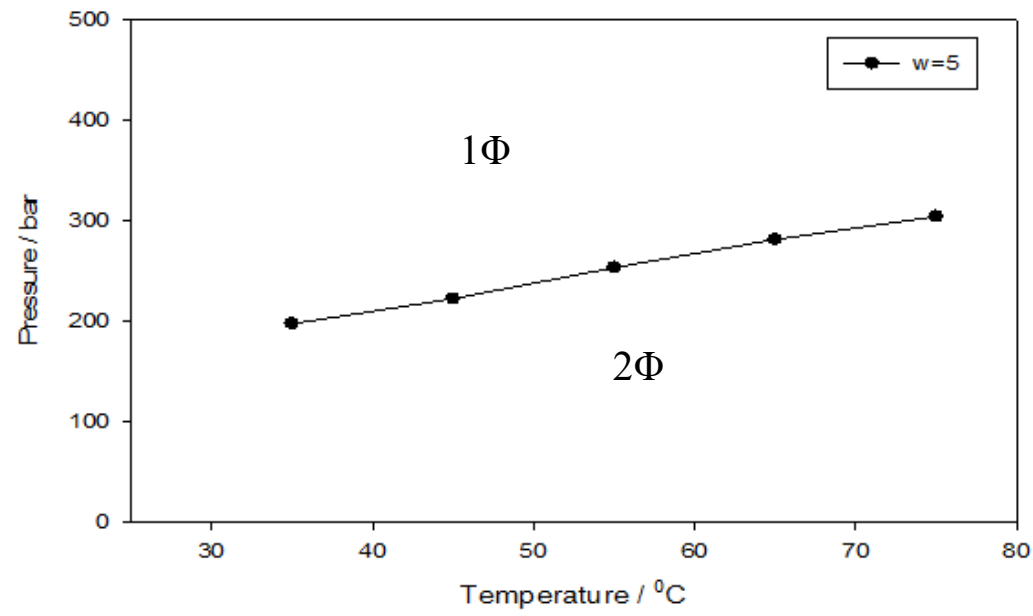

Figure 5 Phase behaviour of $\mathrm{Co}(\mathrm{di}-\mathrm{CF} 2)_{2}$ surfactant in $\mathrm{CO}_{2}$ at various $w$ ratios. [surfactant] $=0.04 \mathrm{~mol} \mathrm{dm}^{-3}$

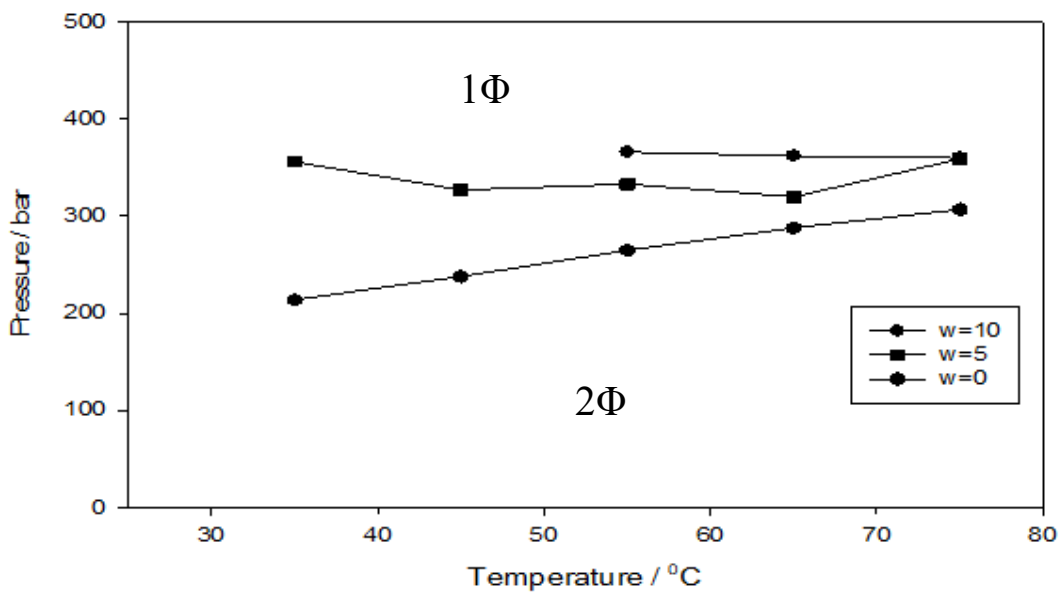

Figure 6 Phase behaviour of $\mathrm{Ni}(\mathrm{di}-\mathrm{CF} 2)_{2}$ surfactant in $\mathrm{CO}_{2}$ at various $w$ ratios. [surfactant] $=0.04 \mathrm{~mol} \mathrm{dm}^{-3}$ 


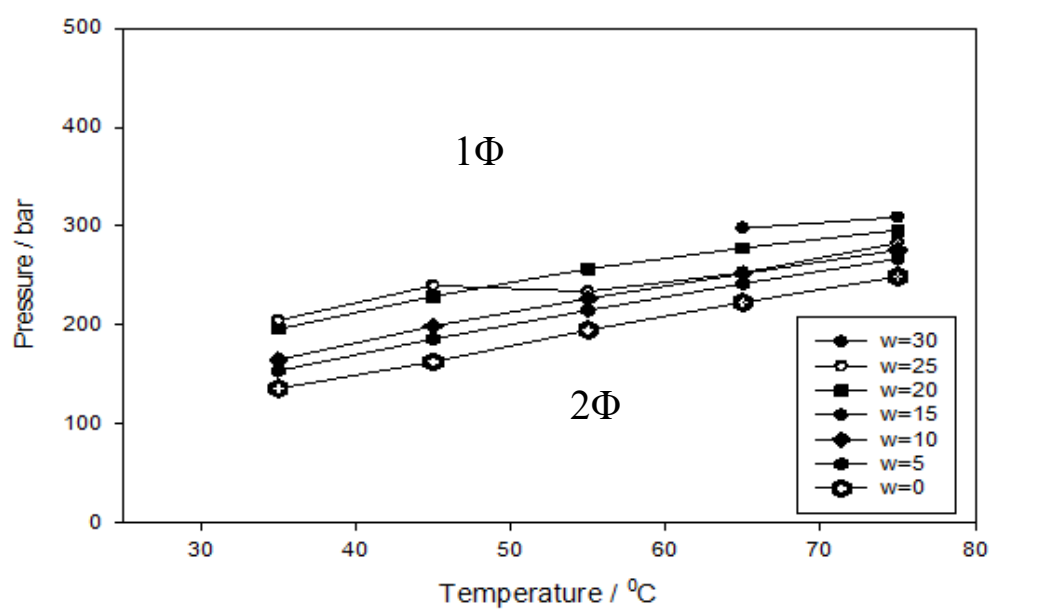

Figure 7 Phase behaviour of $\mathrm{Co}(\mathrm{di}-\mathrm{HCF} 6)_{2}$ surfactant in $\mathrm{CO}_{2}$ at various $w$ ratios. [surfactant] $=0.04 \mathrm{~mol} \mathrm{dm}^{-3}$

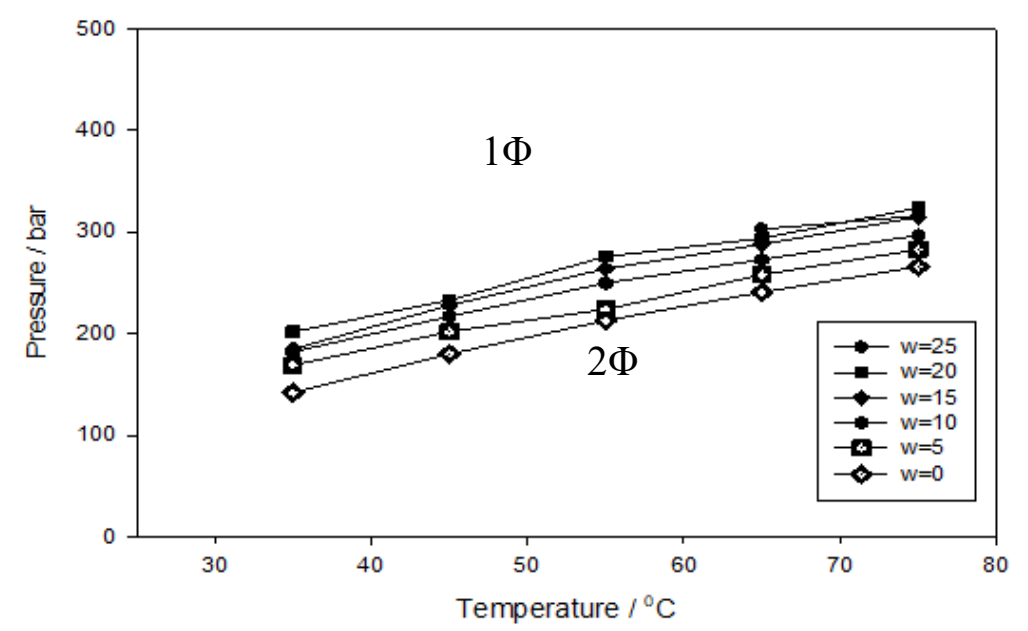

Figure 8 Phase behaviour of $\mathrm{Ni}(\mathrm{di}-\mathrm{HCF} 6)_{2}$ surfactant in $\mathrm{CO}_{2}$ at various $w$ ratios. [surfactant] $=0.04 \mathrm{~mol} \mathrm{dm}^{-3}$

\section{High-Pressure Viscosity of Metallosurfactant- $\mathrm{CO}_{2}$ Systems}

The high-pressure relative viscosities of $\mathrm{CO}_{2}$ systems as a function of different metallosurfactants are shown in Figure $9-10$. These measurements were carried out at a surfactant concentration of $0.02-$ $0.04 \mathrm{~mol} \mathrm{dm}^{-3}$ and in the temperature range $35-75^{\circ} \mathrm{C}$. The viscosity $(\eta)$ data were calculated using the Hagen-Poiseuille equation (Eq. $1-2$ ). Thus, the relative viscosity of the metallosurfactant- $\mathrm{CO}_{2}$ systems $\left(\eta \mathrm{mic} / \eta \mathrm{CO}_{2}\right.$ ) is obtained as follows:

$$
\begin{aligned}
& \eta=\frac{\pi r^{4} t}{8 v l} \\
& \eta_{\text {mid }} / \eta_{\mathrm{CO} 2}=\frac{\eta_{\mathrm{CO}_{2}-\text { hybrid }}}{\eta_{\mathrm{CO}_{2}}}=\frac{{ }_{\mathrm{CO}_{2}-\text { hybrid }}}{P_{\mathrm{CO}_{2}}}
\end{aligned}
$$

$\boldsymbol{\eta}$ : Viscosity $\boldsymbol{\eta}_{\boldsymbol{C O}_{2}}$ : Viscosity of $\mathrm{CO}_{2} \quad \boldsymbol{\eta}_{\boldsymbol{C o}_{2}-\text { hybrid }}$ : Viscosity of compound/ $\mathrm{CO}_{2}$ solution $\mathbf{P}$ : Differential pressure at the inlet and outlet of the capillary $\mathbf{r}$ : Radius of capillary $\mathbf{t}$ : Time $\mathbf{v}$ : Volume of fluid $[\boldsymbol{\eta}]:$ Specific viscosity $\boldsymbol{P}_{\mathbf{C O}_{2}}$ : Differential pressure in the pure $\mathrm{CO}_{2}$ system $\boldsymbol{P}_{\text {Co }_{2}-\text { hybrid }}$ : Differential pressure in the compound $/ \mathrm{CO}_{2}$ solution.

Previously, [22], using di-HCF4, showed a viscosity increase upon the introduction of nickel or cobalt salts, indicating a relationship between the chemical nature of the surfactant and the viscosity 
enhancement. The work presented here, in agreement with that study, shows that $\mathrm{Co}^{2+}$ and $\mathrm{Ni}^{2+} \mathrm{salts}_{\text {of }}$ di-HCF4 resulted in an increase in relative viscosity of up to $90 \%$. Interestingly, increasing the $w$ ratio above $w=10$ in these di-HCF4 surfactants leads to a notable reduction in the relative viscosity. It is clear that the relative viscosity is dependent upon the mild solubility of the surfactant at lower pressures, and its ability to disperse small amounts of water [12].

Recently, efforts to reduce the proportion of fluorine atoms in the surfactant chains e.g. di-CF2 has opened up a new pathway for generating more economic $\mathrm{CO}_{2}$-philic surfactants. Although the sodium version of di-CF2 has been proven to stabilise w/c microemulsions [13], here, the introduction of nickel or cobalt di-CF2 surfactant decreases the microemulsification. Of the three-fluorinated surfactants tested, di-CF2 was not able to stabilise w/c microemulsions with lower relative viscosity at lower $\mathrm{w}$ ratios ( $\mathrm{w}<$ 5). This is not surprising since weak intermolecular interactions between the fluorocarbon tails favour tail- $\mathrm{CO}_{2}$ interactions and contribute to the microemulsifying capacity of fluorinated surfactants [24].

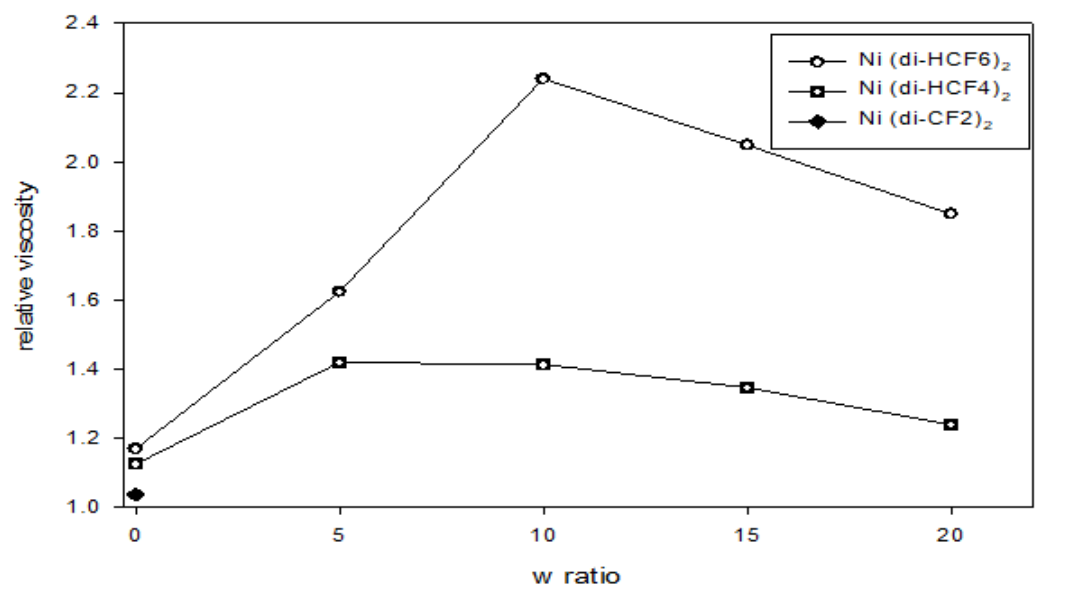

Figure 9 Relative viscosities of $\mathrm{Ni}$ (surfactant) $)_{2}$ variants at [Surfactant $]=0.04 \mathrm{~mol} \mathrm{dm}^{-3}$ in $\mathrm{CO}_{2}$ at $35^{\circ} \mathrm{C}$.

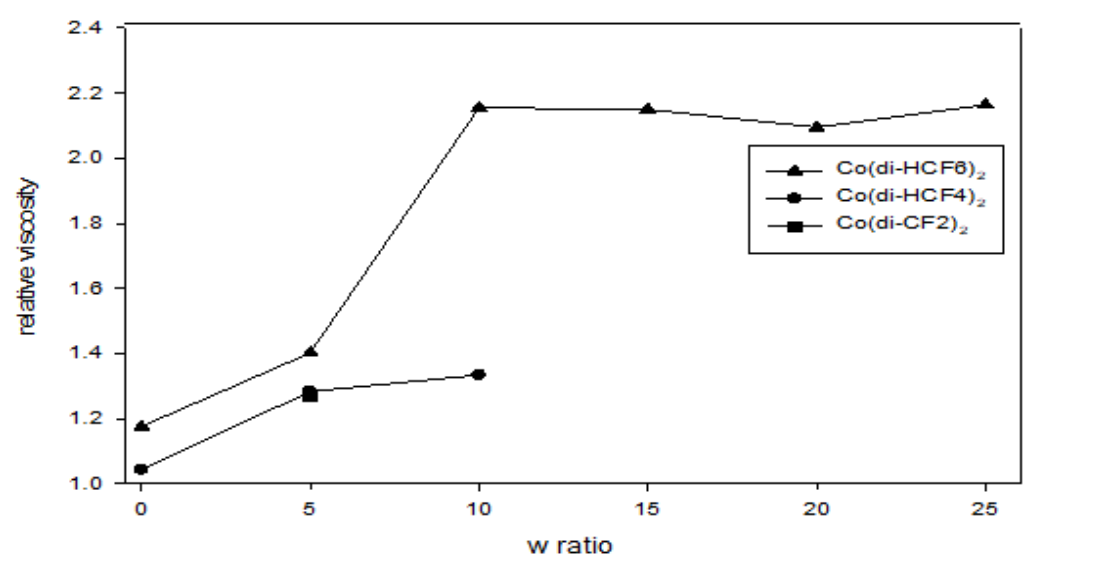

Figure 10 Relative viscosities of $\mathrm{Co}(\text { surfactant })_{2}$ variants at $[$ Surfactant $]=0.04 \mathrm{~mol} \mathrm{dm}^{-3}$ in $\mathrm{CO}_{2}$ at $35^{\circ} \mathrm{C}$. 
Interestingly, $\mathrm{Ni}(\mathrm{diHCF} 6)_{2}$ and $\mathrm{Co}(\mathrm{diHCF} 6)_{2}$ surfactants have the highest relative viscosities. Both surfactants were able to achieve relative viscosity up to 2.10 at a temperature of $35^{\circ} \mathrm{C}$. These experimental results indicate that the viscosity enhancement of $\mathrm{scCO}_{2}$ strongly depends on the microemulsifying properties as well as the fluorine content of the surfactants [24]. The viscosity increased significantly with increasing $w$ ratio up to $w=10$. It was also observed that the relative viscosity of $\mathrm{scCO}_{2}$ tended to decrease as the $w$ ratio increased. In order to clearly distinguish the effect of temperature variation and surfactant concentration, the dependence of the relative viscosity of both parameters was plotted and respectively. It can be seen that the effect of temperature on the relative viscosity values was small, and the temperature varied only within a \pm 0.5 range. However, a decrease in the relative viscosity with increasing surfactant concentration is clearly illustrated.

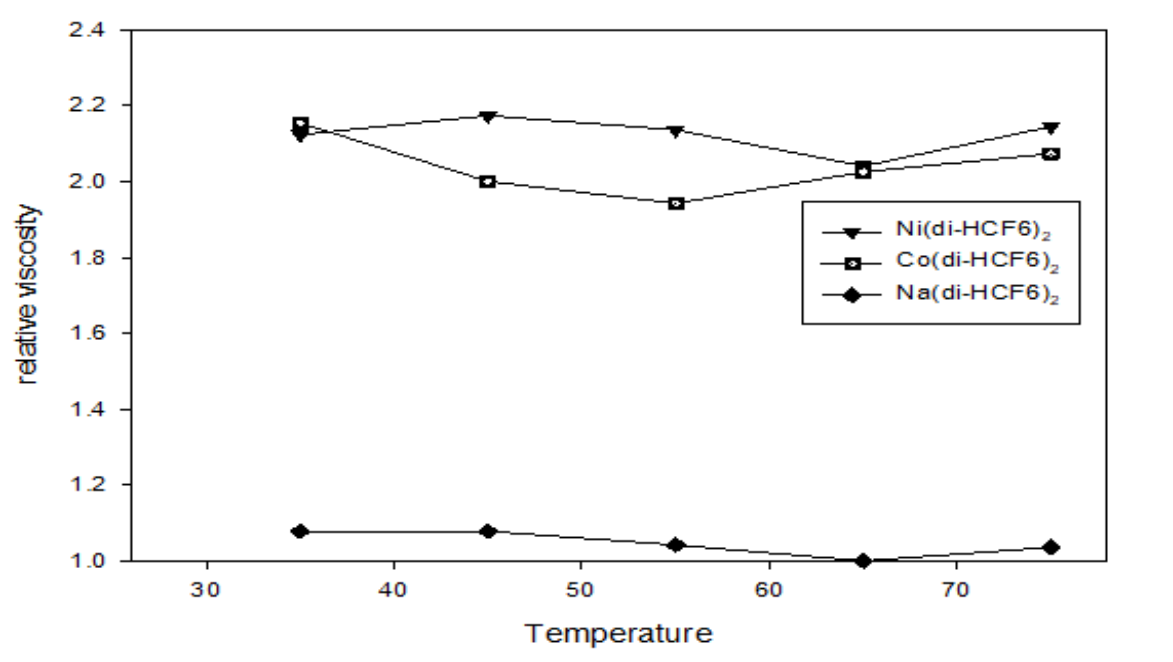

Figure 11 Temperature effect on relative viscosities of di-HCF6 metallosurfactant variants at [Surfactant] $=0.04$ $\mathrm{mol} \mathrm{dm}{ }^{-3}$ in $\mathrm{CO}_{2}$ at $35^{\circ} \mathrm{C}$.

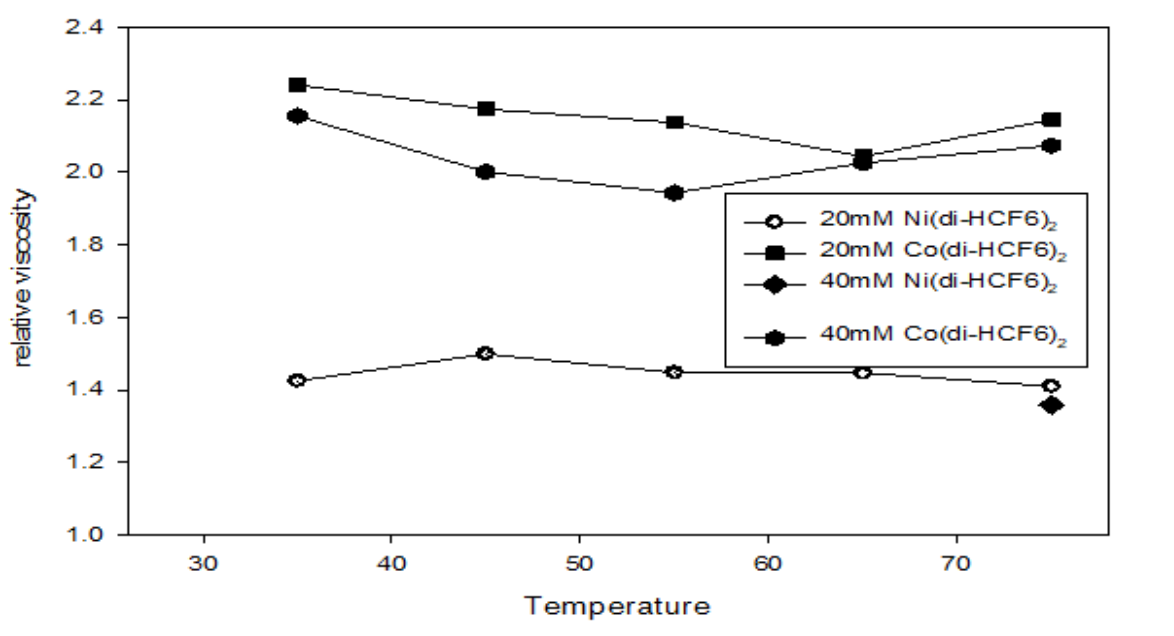

Figure 12 Temperature effect on relative viscosities of di-HCF6 metallosurfactant variants at different [Surfactant] in $\mathrm{CO}_{2}$ at $35^{\circ} \mathrm{C}$.

In Figures $9-12$, all of the relative viscosities are seen to increase with increasing microemulsification capacity of the surfactant, as well as with increasing fluorine content in the surfactants. This behaviour, 
noted before for w/c microemulsions, is indicative of the swelling of micelles with added water [25]. The phase behaviour is consistent with the following scenario: when micelles become swollen with water, attractive micelle-micelle interactions are strengthened, thus higher pressures are required to overcome tail/tail interactions and prevent phase separation. Comparison of the relative viscosity performance with other surfactants as shown in Figure 13 indicate limited water uptake in reverse micelles by the lower fluorine content surfactants. Nevertheless, $\mathrm{Ni}(\mathrm{di}-\mathrm{HCF} 6)_{2}$ and $\mathrm{Co}(\mathrm{di}-\mathrm{HCF} 6)_{2}$ in particular, clearly outperform most other surfactants, exhibiting the highest relative viscosities and allowing stable microemulsion formation. For comparison purposes, lower relative viscosity values have been reported for costly hybrid sulfate surfactants e.g. K-F7H4 [26], the maximum $w$ value being 30.

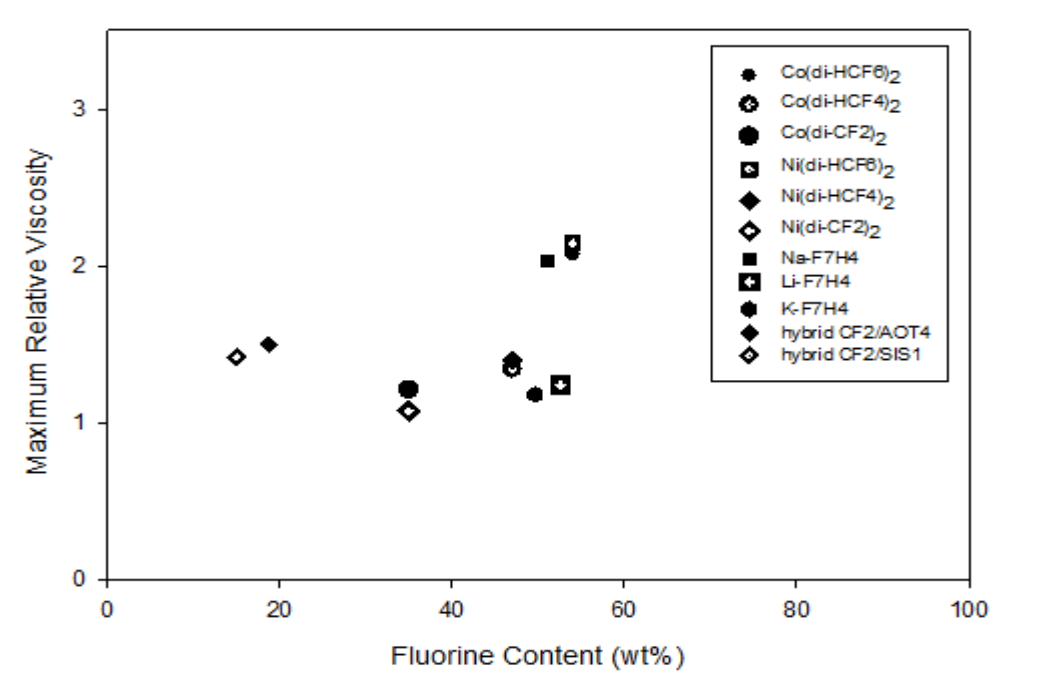

Figure 13 Relationship of maximum relative viscosity with fluorine content of surfactants

\section{CONCLUSIONS}

In this paper, a systematic study was made of metallosurfactant (nickel $\left(\mathrm{Ni}^{2+}\right)$ or cobalt $\left(\mathrm{Co}^{2+}\right)$ counterion) sulfosuccinate surfactants, thus offering an acceptable solution for carbon dioxide viscosity modification in enhanced oil recovery applications. Metallosurfactants were successfully synthesised using three different double chain, fluorinated sulfosuccinate surfactants, namely sodium bis $(4 H, 4 H$, $5 H, 5 H, 5 H$-pentafluoropentyl)-2-sulfosuccinate (di-CF2), sodium bis $(1 H, 1 H, 5 H$-perfluoropentyl)-2sulfosuccinate (di-HCF4) and sodium bis $(1 \mathrm{H}, 1 \mathrm{H}, 7 \mathrm{H}$-perfluoroheptyl)-2-sulfosuccinate (di-HCF6) according to well-documented preparation methods. The surfactant purity (both on the organic and physico-chemical levels) was confirmed by ${ }^{1} \mathrm{H}$ nuclear magnetic resonance, UV-visible spectroscopy and also by elemental analysis (EA). Among these surfactants, the metallosurfactants utilising sodium bis $(1 \mathrm{H}, 1 \mathrm{H}, 7 \mathrm{H}$-perfluoroheptyl)-2-sulfosuccinate (di-HCF6) were the only ones that were able to stabilise w/c microemulsions via the formation of reverse micelles at lower cloud point pressures ( $\mathrm{P}_{\text {trans }}$ ). Interestingly, increasing the fluorine content of di-HCF6 metallosurfactant showed significance increases in the relative viscosity of $\mathrm{CO}_{2}$. di-HCF6 metallosurfactant were able to achieve relative viscosities up to 2.10 at a temperature of $35^{\circ} \mathrm{C}$. Although the sodium version of di-CF2 has been proven to stabilise w/c microemulsions, of the three-fluorinated surfactants tested, di-CF2 metallosurfactants were not able to stabilise $\mathrm{w} / \mathrm{c}$ microemulsions with lower relative viscosity at lower $w$ ratios $(\mathrm{w}<5)$. This observation is not surprising since weak intermolecular interactions between the fluorocarbon tails favour tail- $\mathrm{CO}_{2}$ interactions and contribute to the strongly microemulsifying properties of the fluorinated metallosurfactants. In summary, this work has advanced the understanding of how surfactants can be used to modify the physical properties of liquid carbon dioxide. In particular, it was shown that control 
over solvent viscosity can be achieved using the principles of molecular self-assembly with custom-made $\mathrm{CO}_{2}$ compatible surfactants.

\section{ACKNOWLEDGEMENTS}

The work funded under grants from the Fundamental Research Grant Scheme (FRGS; Grant code: 20150155-101-02) and the Kurita Water and Environment Foundation (Grant Code: 16P003).

\section{REFERENCES}

[1] Young, J.; DeSimone, J. M., \& Tumas, W. (Eds.). (2003). Green chemistry using liquid and supercritical carbon dioxide. Oxford University Press. New York, NY, 228.

[2] Keyes, F. G.; Kirkwood. (1930). Phase Behaviour and its Effects on Reactions in Liquid and Supercritical Carbon Dioxide. Journal Physical Chemistry, 36, 754-761.

[3] Eastoe, J., \& Gold, S. (2005). Self-assembly in green solvents. Physical Chemistry Chemical Physics, 7(7), 1352-1362.

[4] DeSimone, J. M. (2002). Practical approaches to green solvents. Science, 297(5582), 799-803.

[5] Adam, D. (2000). Clean and green. But are they mean? Nature 407, 938-940.

[6] Shi, C., Huang, Z., Beckman, E. J., Enick, R. M., Kim, S. Y., \& Curran, D. P. (2001). Semi-fluorinated trialkyltin fluorides and fluorinated telechelic ionomers as viscosity-enhancing agents for carbon dioxide. Industrial \& engineering chemistry research, 40(3), 908-913.

[7] Ohde, H., Wai, C. M., Kim, H., Kim, J., \& Ohde, M. (2002). Hydrogenation of olefins in supercritical $\mathrm{CO}_{2}$ catalyzed by palladium nanoparticles in a water-in- $\mathrm{CO}_{2}$ microemulsion. Journal of the American Chemical Society, 124(17), 4540-4541.

[8] Ohde, M., Ohde, H., \& Wai, C. M. (2005). Recycling nanoparticles stabilized in water-in- $\mathrm{CO}_{2}$ microemulsions for catalytic hydrogenations. Langmuir, 21(5), 1738-1744.

[9] Mark D. Doherty, Jason J. Lee, Aman Dhuwe, Michael J. O’Brien, M. J., Perry, R. J., Beckman, E. J., \& Enick, R. M. (2016). Small Molecule Cyclic Amide and Urea Based Thickeners for Organic and $\mathrm{sc}-\mathrm{CO}_{2} /$ Organic Solutions. Energy \& Fuels, 30(7), 5601-5610.

[10] Huang, Z., Shi, C., Xu, J., Kilic, S., Enick, R. M., \& Beckman, E. J. (2000). Enhancement of the viscosity of carbon dioxide using styrene/fluoroacrylate copolymers. Macromolecules, 33(15), 5437-5442.

[11] McClain, J. B., London, D., Combes, J. R., Romack, T. J., Canelas, D. A., Betts, D. E., ... \& DeSimone, J. M. (1996). Solution properties of a $\mathrm{CO}_{2}$-soluble fluoropolymer via small angle neutron scattering. Journal of the American Chemical Society, 118(4), 917-918.

[12] Trickett, K., Xing, D., Eastoe, J., Enick, R., Mohamed, A., Hollamby, M. J., ... \& Heenan, R. K. (2010). Hydrocarbon metallosurfactants for $\mathrm{CO}_{2}$. Langmuir, 26(7), 4732-4737.

[13] Mohamed, A.; Sagisaka, M.; Guittard, F.; Cummings, S.; Paul, A.; Rogers, S. E.; Heenan, R. K.; Dyer, R.; Eastoe, J., Low Fluorine Content CO2-philic Surfactants. Langmuir 2011, 27, (17), 10562-10569.

[14] Mohamed, A., Ardyani, T., Sagisaka, M., Ono, S., Narumi, T., Kubota, M., \& Hashim, N. (2015). Economical and Efficient Hybrid Surfactant with Low Fluorine Content for the Stabilisation of Water-in- $\mathrm{CO}_{2}$ Microemulsions. The Journal of Supercritical Fluids, 98, 127-136.

[15] Mohamed, A., Ardyani, T., Bakar, S. A., Sagisaka, M., Ono, S., Narumi, T. \& Eastoe, J. (2016). Effect of surfactant headgroup on low-fluorine-content $\mathrm{CO}_{2}$-philic hybrid surfactants. The Journal of Supercritical Fluids, 116, 148-154.

[16] Eastoe, J., Fragneto, G., Robinson, B. H., Towey, T. F., Heenan, R. K., \& Leng, F. J. (1992). Variation of surfactant counterion and its effect on the structure and properties of Aerosol-OT-based water-in-oil microemulsions. Journal of the Chemical Society Faraday Transactions, 88(3), 461-471.

[17] Eastoe, J., Steytler, D. C., Robinson, B. H., \& Heenan, R. K. (1994). Pressure-induced structural changes in water-in-propane microemulsions. Journal of the Chemical Society, Faraday Transactions, 90(20), 3121-3127.

[18] Eastoe, J., Robinson, B. H., \& Heenan, R. K. (1993). Water-in-oil microemulsions formed by ammonium and tetra propylammonium salts of Aerosol OT. Langmuir, 9(11), 2820-2824.

[19] Sagisaka, M., Hino, M., Oasa, J., Yamamoto, M., Yoda, S., Takebayashi, Y., ... \& Otake, K. (2009). Characterization of water/supercritical $\mathrm{CO}_{2}$ microemulsion by UV-visible spectroscopy and dynamic light scattering. Journal of oleo science, 58(2), 75-83.

[20] Sagisaka, M., Yoda, S., Takebayashi, Y., Otake, K., Kitiyanan, B., Kondo, Y., ... \& Abe, M. (2003). Preparation of a W/scCO ${ }_{2}$ microemulsion using fluorinated surfactants. Langmuir, 19(2), 220-225. 
[21] Takahashi, R., Sato, S., Sodesawa, T., \& Nishida, H. (2002). Effect of pore size on the liquid-phase pore diffusion of nickel nitrate. Physical Chemistry Chemical Physics, 4(15), 3800-3805.

[22] Trickett, K., Xing, D., Enick, R., Eastoe, J., Hollamby, M. J., Mutch, K. J., ... \& Steytler, D. C. (2009). Rodlike micelles thicken $\mathrm{CO}_{2}$. Langmuir, 26(1), 83-88.

[23] Eastoe, J., Downer, A., Paul, A., Steytler, D. C., Rumsey, E., Penfold, J., \& Heenan, R. K. (2000). Fluorosurfactants at air/water and water/ $\mathrm{CO}_{2}$ interfaces. Physical Chemistry Chemical Physics, 2(22), 5235-5242.

[24] Dalvi, V. H., Srinivasan, V., \& Rossky, P. J. (2010). Understanding the effectiveness of fluorocarbon ligands in dispersing nanoparticles in supercritical carbon dioxide. The Journal of Physical Chemistry C, 114(37), 15553-15561.

[25] Eastoe, J., Cazelles, B. M., Steytler, D. C., Holmes, J. D., Pitt, A. R., Wear, T. J., \& Heenan, R. K. (1997). Water-in- $\mathrm{CO}_{2}$ microemulsions studied by small-angle neutron scattering. Langmuir, 13(26), 6980-6984.

[26] Cummings, S., Xing, D., Enick, R., Rogers, S., Heenan, R., Grillo, I., \& Eastoe, J. (2012). Design principles for supercritical CO 2 viscosifiers. Soft Matter, 8(26), 7044-7055. 